\title{
Examining the Link Between Academic Achievement and Adolescent Bullying: A Moderated Moderating Model
}

This article was published in the following Dove Press journal:

Psychology Research and Behavior Management

\author{
Qing Xiong (D) \\ Shuping $\mathrm{Shi}^{2}$ \\ Jianwen $\mathrm{Chen}^{3}$ \\ Yiqiu $\mathrm{Hu}^{4}$ \\ Xintong Zheng ${ }^{3}$ \\ Congcong $\mathrm{Li}^{5}$ \\ Quanlei $\mathrm{Yu}^{5-7}$
}

'Institute of Developmental Psychology, Beijing Normal University, Beijing, People's Republic of China; ${ }^{2}$ RDFZ Chaoyang Branch School, Beijing, People's Republic of China; ${ }^{3}$ Graduate School of Education, Huazhong University of Science and Technology, Wuhan, Hubei, People's Republic of China; ${ }^{4}$ School of Educational Science, Hunan Normal University, Changsha, Hunan, People's Republic of China; ${ }^{5}$ School of Psychology, Central China Normal University, Hubei, Wuhan, People's Republic of China; ${ }^{6}$ Key Laboratory of Adolescent

Cyberpsychology and Behavior (CCNU), Ministry of Education, Wuhan, Hubei,

People's Republic of China; ${ }^{7}$ Central China Normal University Branch, Collaborative Innovation Center of Assessment Toward Basic Education Quality, Wuhan, Hubei, People's Republic of China

Correspondence: Quanlei Yu School of Psychology, Central China Normal University, No. 152 Luoyu Road, Hongshan District, Wuhan, Hubei 430079, People's Republic of China Tel +86-027-67868617

Email yuleil9881987@mail.ccnu.edu.cn
Purpose: Bullying is a serious problem among adolescents. Many scholars have examined school bullying in recent years; however, there are many psychological and behavioral mechanisms for bully that still remain unclear. Based on the theory of self-worth orientation, this study examined the influence of academic achievement on bullying behavior among adolescents and explored the moderating effects of perceived social support and age cohort. Methods: Participants were 3227 middle and high school students in the 7th through 12th grades in China. A self-report method was used to measure academic achievement, social support, bullying, and demographic variables.

Results: Moderation analyses indicated that the relationship between academic achievement and bullying behavior was moderated by the perceived social support of adolescents and their age cohort. Specifically, social support moderated the relationship between achievement and bullying behavior positively in the middle school group but negatively in the high school group.

Conclusion: The results support the hypothesis of self-worth orientation theory and indicate that bullying intervention could be enhanced by addressing the relationships between academic achievement, social support, age cohort, and bullying.

Keywords: academic achievement, bully, social support, age cohort, self-worth

\section{Introduction}

Bullying is one of the most common problems in schools. According to a survey conducted across 25 countries, between $9 \%$ and $54 \%$ of primary and secondary school students are involved in bullying in school, ${ }^{1}$ and a recent study suggested that the percentage may be even higher. ${ }^{2}$ In China, many studies have shown about $20 \%{ }^{3,4}$ which is not negligible. Regarding the relationship between bullying and academic achievement, previous studies focused more on the problems of the victims $^{5,6}$ than of the bullies. ${ }^{7}$ In general, bullying has been characterized as being purposeful and continual and involves an imbalance of power. ${ }^{8,9}$ Bullying negatively affects not only the victims, ${ }^{10,11}$ but also the development of the bullies. $^{12}$ The psychological and behavioral mechanisms of bullying behavior have attracted attention from many scholars. ${ }^{13}$ Most studies have shown that academic achievement has a significant negative correlation with bullying behavior, ${ }^{14,15}$ but some have pointed out that low academic achievement was not a predictor of bullying behavior. ${ }^{16,17}$ The complex relationship between academic achievement and bullying merits further study. ${ }^{7}$ 


\section{Relationship Between Academic Achievement and Bullying}

The theory of self-worth orientation posits that self-worth is the ultimate motivation for human behavior, that it is necessary to construct and interpret internal and external explanation systems, and that discovering one's identity and life meaning is essential. ${ }^{18,19}$ When individuals cannot obtain sufficient self-worth support in their normal lives, they pursue other pathways to improve their self-worth, such as joining delinquent gangs or indulging in the online world. ${ }^{19,20}$

Academic development is an important task for adolescents. $^{21}$ In Chinese culture, academic achievement has been emphasized for nearly a thousand years, beginning with the Imperial Examination System known as "Keju." 22 The ideas that "to be a scholar is to be at the top of society" and "being a farmer in the morning and an official under the emperor's lead in the evening" remain influential in China today. For example, China's current education system is dominated by a rigorous exam-oriented model, which makes academic achievement even more critical to an individual's self-worth. ${ }^{23}$ Researchers believe that bullies resort to bullying to gain superiority, popularity, and dominance. ${ }^{24-28}$ According to the self-worth orientation theory, there is a compensatory mechanism among self-worth-supporting resources. When one resource is lacking, other resources can play a compensatory role. ${ }^{20}$ Previous studies have shown that students with lower levels of academic competence are more likely to display conduct problems such as aggression, bullying, and substance abuse. ${ }^{29-32}$ Therefore, individuals with poor academic achievement may use bullying to gain self-worth.

\section{Moderating Effect of Perceived Social Support}

Social support is an important bracing resource for an

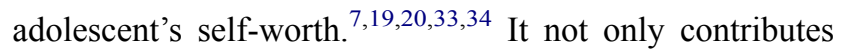
to healthy behavior, ${ }^{35,36}$ but also moderates the relationship between adolescent stress and health. ${ }^{37-40}$ According to the self-worth orientation theory, self-worth is mainly derived from self-worth support systems-including personal achievement, social status, and trust and acceptance from significant others - and these bracing sources of selfworth compensate for each other. ${ }^{7,19,20,33,34,41}$ Therefore, adolescents' perceived social support might moderate the effect of academic achievement on bullying behavior (Hypothesis 1). Specifically, individuals who perceive a lower level of social support may depend more on academic achievement; subsequently, the impact of academic achievement on bullying could greatly increase. On the contrary, individuals who perceive a higher level of social support may exhibit a lower level of bullying behavior even if their academic achievement is poor; thus, the impact of academic achievement on bullying is reduced.

\section{Moderated Moderating Effect of Age Cohort}

From the perspective of adolescent development, the moderating effect of perceived social support on the relationship between academic achievement and bullying may differ for middle and high school students. For middle school students, social support contributes to self-worth. ${ }^{37}$ A higher level of social support is conducive to alleviating pressure on adolescents. ${ }^{39,40,42}$ Therefore, social support may attenuate the impact of academic achievement on bullying.

The urge to explore self-identity becomes stronger among high school students, ${ }^{43}$ and seeking group identity becomes a strong motivation. ${ }^{44,45}$ Bullying in high school might be increasingly dependent on the influence of social groups (eg, physical aggression declines, and relational aggression increases) ${ }^{46}$ rather than on a bully's physical strength, as in primary or middle school. ${ }^{47}$ Social support in high schools may enhance one's self-worth, but may provide psychological support for bullying as a secondary effect. ${ }^{48}$ Therefore, social support might strengthen the effects of academic achievement on bullying. Based on previous findings, this study hypothesizes that (Hypothesis 2) social support can moderate the relationship between academic achievement and bullying behaviors in adolescents and that the moderating effect of social support may be further moderated by age cohort (Figure 1).

\section{The Present Study}

Middle and high school students were recruited as participants for this study to explore the moderating roles of perceived social support of adolescents and age cohort in the relationship between academic achievement and bullying. Previous studies have shown that aggressive behavior, which is highly related to bullying, is influenced by gender $^{25,49-52}$ and physical stature, ${ }^{53,54}$ thus, this study considered these to be control variables.

\section{Methods}

\section{Participants}

A total of 3227 middle and high school students were recruited from Guangdong, Jiangsu, Zhejiang, and Hubei 


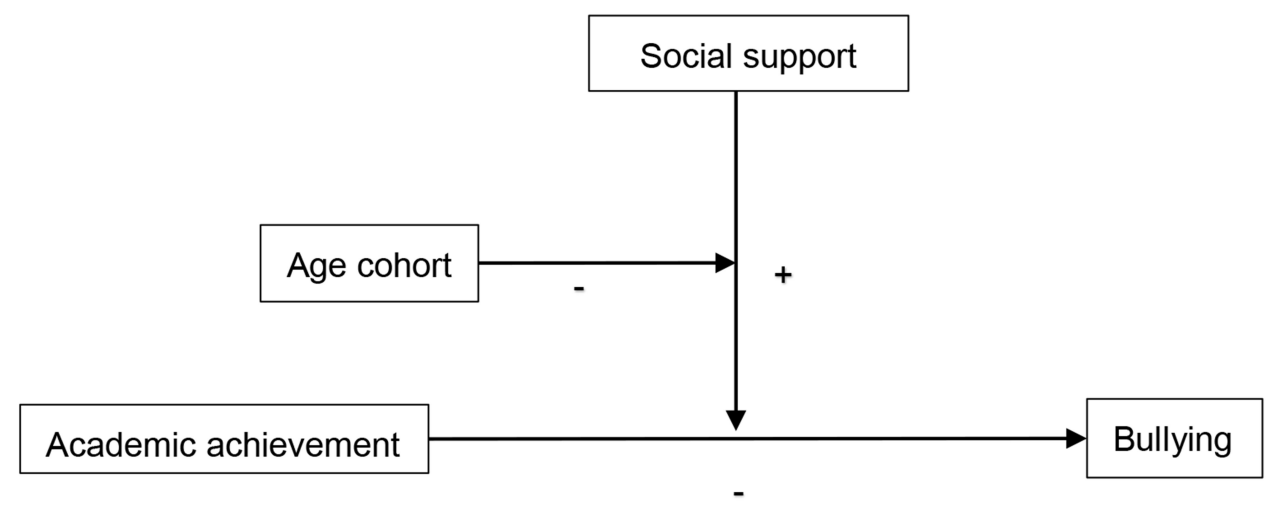

Figure I The moderating effect of social support and age cohort on the relationship between academic achievement and bullying.

provinces in China. Among them, 2092 were middle school students (1065 boys), and 1135 were high school students (551 boys). The average age of the students was $15.12(\mathrm{SD}=1.70)$. The study was reviewed and approved by the local ethics committee, and the methodology used followed government regulations and laboratory policies.

\section{Measures}

\section{Academic Achievement}

As suggested by $\mathrm{Li}^{6}{ }^{6}$ academic achievement was measured using a single item: "Where do you rank in your class?" The item was rated on a 5 -point scale (" 1 " = the first $20 \%$, "2" = $20-40 \%, " 3 "=40-60 \%, " 4 "=60-80 \%$, and " $5 "=$ the last $20 \%$ ). The scores were reversed prior to analysis to improve interpretation and understanding. Given that students' academic achievement is a relatively objective result, several studies have used a single item to reflect students' academic performance. ${ }^{55,56}$ Based on the high consistency between students' self-reported academic ranks and official records of their academic achievement ${ }^{57,58}$ and the psychometric reliability of single-item questionnaires,${ }^{59}$ this study applied a single item to reflect students' academic achievement.

\section{Bullying}

Bullying was assessed using the Bullying subscale from the Revised Olweus Bully/Victim Questionnaire. ${ }^{60}$ This scale contains six items (eg, "I kept him/her out of things on purpose, excluded him/her from my group of friends, or completely ignored him/her;" "I took money or other things from him/her or damaged his/her belongings,"). Participants also rated frequency on a 5-point Likert scale, wherein 1 indicated "no bullying happened this semester," 2 indicated "bullying only happened once or twice," 3 indicated "bullying happened two or three times a month," 4 indicated "bullying happened about once a week," and 5 indicated "bullying happened several times a week." This scale has acceptable reliability and validity in China. ${ }^{61,62}$ In this study, the alpha coefficient and split-half reliability were 0.97 and 0.96 , respectively.

\section{Perceived Social Support}

Perceived social support was measured using a scale revised by Jiang based on the Multidimensional scale of perceived social support. ${ }^{33,63}$ The original scale included support from family, friends, and others. Through factor analysis, Jing and his colleagues found that the scale could be condensed into two basic dimensions: internal family support and external support. The former factor contains four items (eg, "I can get emotional help and support from my family when I need it," "My family can give me practical help," and so on). The latter factor contains eight items (eg, "Some people [leaders, relatives, colleagues] appear when I encounter problems," and "I can share happiness and good or bad feelings with some people [leaders, relatives, colleagues]."). Participants rated these factors on a 7-point Likert scale ranging from 1 (strongly disagree) to 7 (strongly agree). Previous studies have shown that the scale has acceptable reliability and validity in China. ${ }^{64,65}$ In the present study, the alpha coefficient and split-half reliability of the scale were 0.95 and 0.93 , respectively.

\section{Demographic Variables}

The demographic information involved were participants' grades ("What grade are you in?"), gender ("What is your gender?"), and height (“What is your height?") variables.

\section{Procedure}

First, researchers recruited and trained teachers and school administrators as research assistants. Second, a link to the 
questionnaire was sent to research assistants via QQ or WeChat. Finally, the students were required to complete the questionnaire online after they had consented to participate in this study.

\section{Data Analysis}

SPSS 19.0 was used for data analysis. First, a correlation analysis was conducted to provide an overall descriptive analysis. Then, a stepwise regression model was used to investigate the moderating effects of social support and age cohort on the relationship between academic achievement and bullying. Finally, a simple slope effect test was conducted to further explore the relationship between academic achievement and bullying under limited conditions.

Harman's single factor test was used to investigate the common method bias. ${ }^{66}$ The first factors explained by the unrotated and rotated variables were $35.45 \%$ and $26.58 \%$, respectively. Both were below the critical $40 \%$ threshold. Therefore, the common method bias effect was not significant in this study.

\section{Results}

\section{Preliminary and Descriptive Analysis}

Previous studies have demonstrated that the physical height of students correlates with the level of aggression. $^{53,54}$ For developing adolescents, physical stature should refer to average height in their peer group rather than absolute height. Therefore, we standardized the height in each grade. To facilitate the subsequent regression analysis, age cohort and gender were dummy coded (middle school student $=0$, high school student $=1$; boy $=0$, girl = 1).

As shown in Table 1, the correlations of gender, height, and age cohort with adolescent bullying behavior were statistically significant and in the expected direction, while the relationship between academic achievement and bullying was not significant, which may be due to the masking effect of moderating variables.

A one-sample $t$-test was adopted, and the results showed that the mean scores for academic performance were significantly higher than the corresponding midpoints (3), $\mathrm{t}=25.57, \mathrm{p}<0.001$.

\section{The Moderating Effect and Moderated Moderating Effect Analyses}

A stepwise regression analysis was conducted to explore the moderating effect of perceived social support and the moderated moderating effect of age cohort on the impact of academic achievement on bullying. First, the participants' gender and relative height were included in the regression equation. Then, academic achievement, social support, and age cohorts were entered into the regression equation. Finally, the two-way interactions of achievement and social support, achievement and age cohort, social support and age cohort, and the three-way interaction of achievement, social support, and age cohort were included in the regression equation.

As shown in Table 2, bullying behavior among boys was significantly higher than among girls, and bullying behavior among high school students was significantly lower than among middle school students. Relative height positively predicted adolescents' bullying behavior, and academic achievement and social support negatively predicted bullying behavior. Furthermore, the interactions of achievement and social support, achievement and age cohort, and social support and age cohort significantly predicted bullying behavior, in line with the first hypothesis. Notably, the effect of the three-way interaction of achievement and social support and age cohorts on bullying behavior was significant. This finding supports our second hypothesis, which states that social support moderates the influence of academic achievement on the bullying behavior of adolescents, and the moderating effect is further regulated by age cohort.

Table I Descriptive Statistics and Correlations Among Variables in the Whole Sample $(N=3227)$

\begin{tabular}{|l|l|l|l|l|l|l|}
\hline & $\mathbf{M} \pm$ SD & I & $\mathbf{2}$ & $\mathbf{3}$ & $\mathbf{4}$ \\
\hline I. Gender & $0.50 \pm 0.50$ & - & & & \\
2. Stature & $0.00 \pm 1.00$ & $-0.53^{* * *}$ & - & & \\
3. Academic achievement & $3.59 \pm 1.32$ & 0.03 & 0.02 & - & \\
4. Perceived social support & $4.95 \pm 1.21$ & $-0.06^{* * *}$ & $0.04^{*}$ & $0.11^{* * *}$ & - \\
5. Age cohort & $0.35 \pm 0.48$ & 0.02 & $<0.01$ & $-0.06^{* *}$ & $0.06^{* * *}$ & - \\
6. Bullying & $1.25 \pm 0.70$ & $-0.18^{* * *}$ & $0.13^{* * *}$ & -0.02 & 0.01 & $-0.08^{*}$ \\
\hline
\end{tabular}

Notes: ${ }^{* * *} \mathrm{p}<0.001,{ }^{* *} \mathrm{p}<0.01,{ }^{*} \mathrm{p}<0.05$. 
Table 2 The Regression of Academic Achievement on Bullying ( $N=3227)$

\begin{tabular}{|c|c|c|c|c|c|c|}
\hline \multirow{4}{*}{ Predictor variable } & \multicolumn{6}{|c|}{ Outcome Variable: Bullying } \\
\hline & \multicolumn{6}{|c|}{ Standardized Regression Coefficients } \\
\hline & \multicolumn{2}{|c|}{ (model I) } & \multicolumn{2}{|c|}{ (model 2$)$} & \multicolumn{2}{|c|}{ (model 3) } \\
\hline & B & $S E$ & B & $S E$ & B & $S E$ \\
\hline Constant & $1.36 * * *$ & 0.02 & $1.42 * * *$ & 0.06 & $1.81 * * *$ & 0.16 \\
\hline Gender & $-0.23 * * *$ & 0.03 & $-0.22^{* * *}$ & 0.03 & $-0.22^{* * *}$ & 0.03 \\
\hline Stature & $-0.03^{\dagger}$ & 0.01 & $-0.03^{*}$ & 0.01 & $0.03^{\dagger}$ & 0.01 \\
\hline$R^{2}$ & $0.035^{* * *}$ & & & & & \\
\hline Academic achievement (AA) & & & -0.01 & 0.01 & $-0.36 * * *$ & 0.11 \\
\hline Perceived social support (PSS) & & & 0.01 & 0.01 & $-0.28 * * *$ & 0.09 \\
\hline Age cohort & & & $-0.12 * * *$ & 0.03 & $-1.07 * * *$ & 0.32 \\
\hline$R^{2}$ & & & $0.042 * * *$ & & & \\
\hline$\Delta R^{2}$ & & & $0.007^{* * *}$ & & & \\
\hline $\mathrm{AA} \times \mathrm{PSS}$ & & & & & $0.07 * *$ & 0.02 \\
\hline AA $\times$ Age cohort & & & & & $0.24 * *$ & 0.09 \\
\hline PSS $\times$ Age cohort & & & & & $0.20 * *$ & 0.06 \\
\hline AA $\times$ PSS $\times$ Age cohort & & & & & $-0.05^{* *}$ & 0.02 \\
\hline$R^{2}$ & & & & & $0.045 * * *$ & \\
\hline$\Delta R^{2}$ & & & & & $0.003 * * *$ & \\
\hline
\end{tabular}

Note: $* * * p<0.001, *^{*} p<0.01, * p<0.05,{ }^{\dagger}<0.10$

As per the recommendations of Aiken, West, and Reno, ${ }^{67}$ a simple slope effect test was conducted to further investigate the moderating mechanisms of social support on the impact of academic achievement on bullying behavior under limited conditions.
Figure 2 demonstrates that perceived social support significantly and positively moderated the relationship between academic achievement and bullying behavior (B $=0.022, \mathrm{SE}=0.009, \mathrm{t}=2.53, \mathrm{p}<0.05)$ in the middle school group. Further analysis found that the effect of

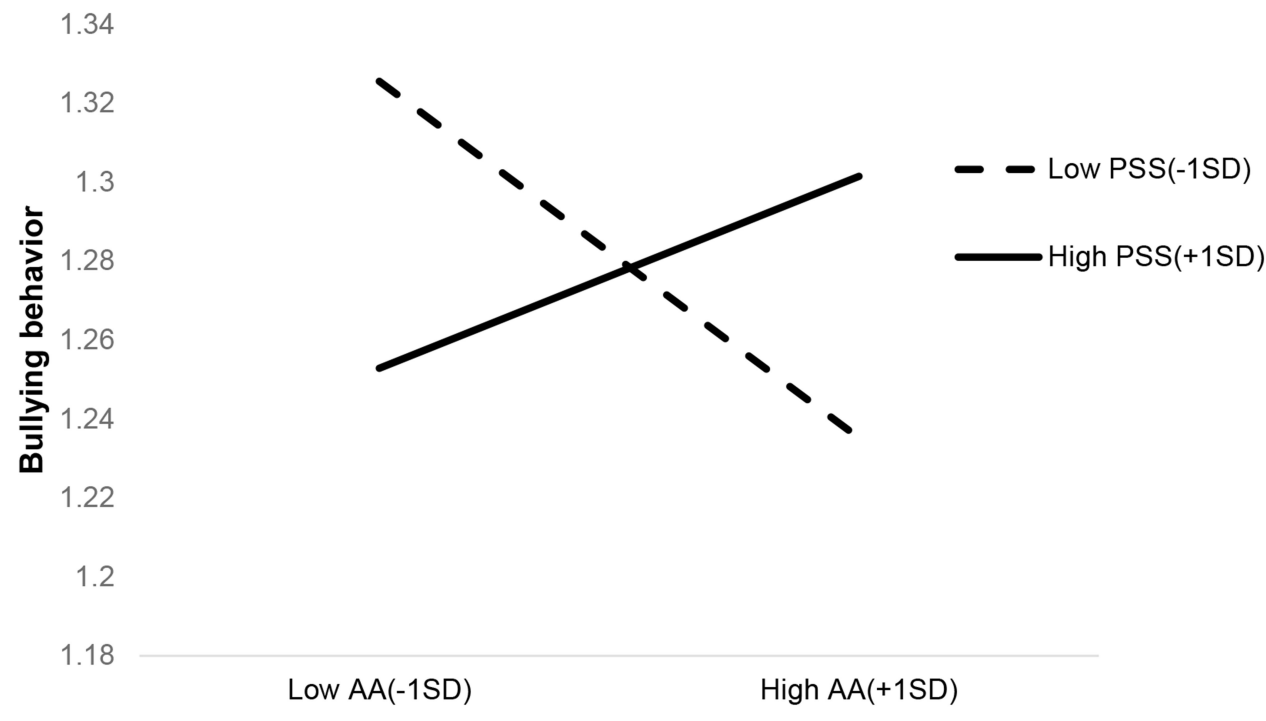

Academic Achievement

Figure 2 The effect of the interaction between perceived social support and academic achievement on bullying in middle school.

Abbreviations: PSS, perceived social support; AA, academic achievement; SD, standard deviation. 
academic achievement on bullying was not significant (B $=0.019, \mathrm{SE}=0.017, \mathrm{t}=1.12, \mathrm{p}=0.26$ ) for the group with higher perceived social support, whereas, in the group with lower perceived social support, the effect of academic achievement on bullying behavior was significant $(\mathrm{B}=$ $-0.034, \mathrm{SE}=0.015, \mathrm{t}=-2.35, \mathrm{p}=0.019)$.

However, in the high school group, perceived social support marginally significantly and negatively moderated the relationship between academic achievement and bullying $(\mathrm{B}=-0.028, \mathrm{SE}=0.015, \mathrm{t}=-1.92, \mathrm{p}=0.055)$. A simple slope effect test conducted among the group that received a higher level of social support (Figure 3) shows that academic achievement significantly negatively predicted bullying $(\mathrm{B}=-0.05, \mathrm{SE}=0.023, \mathrm{t}=-2.20, \mathrm{p}=0.03)$. Conversely, in the group receiving a lower level of social support, academic achievement did not predict bullying at a significant level $(\mathrm{B}=0.018, \mathrm{SE}=0.024, \mathrm{t}=0.76, \mathrm{p}=0.45)$.

\section{Discussion}

Consistent with some previous studies, ${ }^{16,17}$ this study did not find a significant correlation between academic achievement and bullying behavior in adolescents. This was not due to the deny compensation mechanism between academic achievement and bullying according to the selfworth orientation theory, but implies that there are more complex factors involved in bullying behavior. One possible explanation may be derived from the main findings of this study, wherein social support perceived by adolescents moderated the relationship between academic achievement and bullying, and the moderating effect of perceived social support was further moderated by age cohort.

\section{Academic Achievement and Bullying: The Moderating Role of Social Support}

The theory of self-worth orientation assumes that humans are reasonable and socialized animals, and self-worth is a crucial motivator driving human behavior. ${ }^{7,19,20,33,34,41}$ For students, academic achievement is one of the most important sources of self-worth. ${ }^{23}$ Chinese culture emphasizes the importance of academic development, further linking academic achievement and self-worth. Meanwhile, as an instrumental action, one goal of bullying is to gain respect and acceptance from others. ${ }^{68,69}$ According to the self-worth orientation theory, the ultimate purpose of bullying is to pursue self-worth. Although this method is not accepted by dominant social culture, adolescents still adopt bullying behavior as a compensatory method to maintain their self-worth. When adolescents are unable to develop self-worth through conventional means (for example, due to academic difficulties), they resort to other methods that may not be accepted by parents, schools, and society in general. Similarly, the Selection, Optimization, and Compensation Model by Baltes and Baltes suggests that adolescence is an ontogenetic period that is characterized by plasticity, such that when adolescents experience decline or loss, they compensate for this through various means. ${ }^{70}$

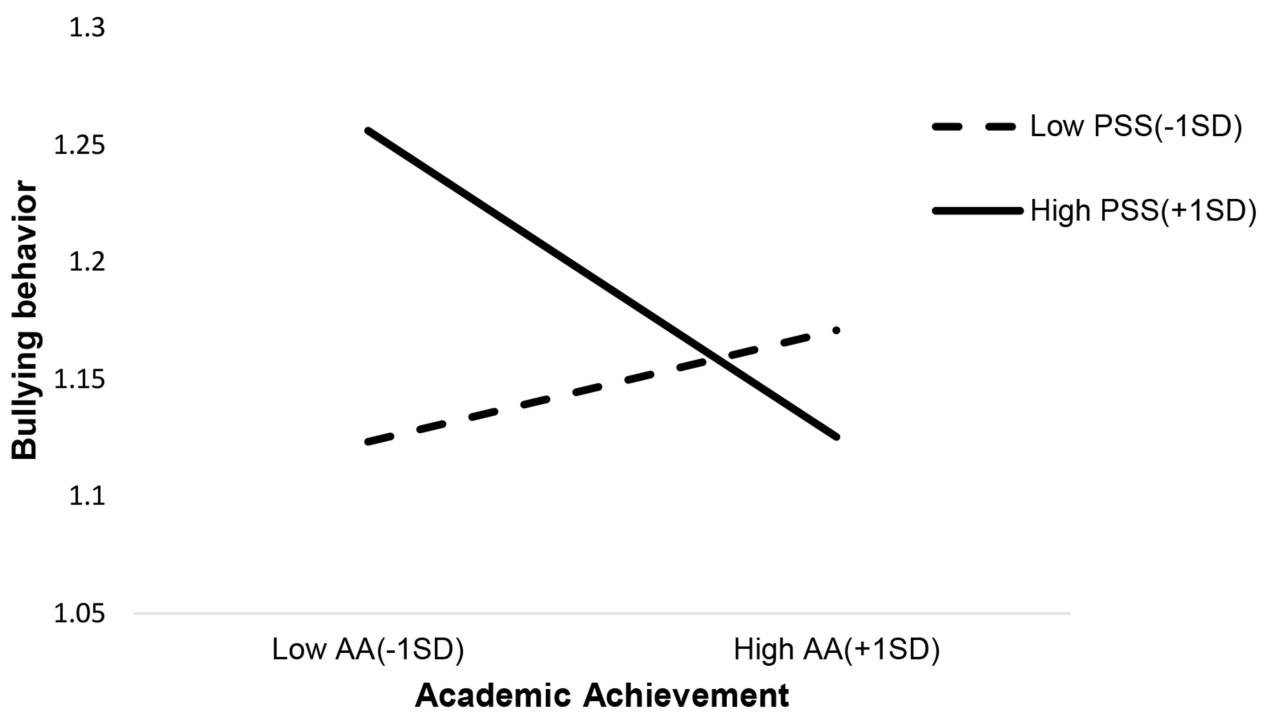

Figure 3 The effect of the interaction between perceived social support and academic achievement on bullying in high school. Abbreviations: PSS, perceived social support; AA, academic achievement; SD, standard deviation. 
In addition to academic achievement, other important support sources of self-worth include socioeconomic status and the trust and support of significant others. ${ }^{18}$ Various resources of support for self-worth compensate for one another. Therefore, the promotion of self-worth by social support can compensate for the low self-worth caused by poor academic achievement and can moderate the relationship between academic achievement and bullying. This is consistent with Jin's early research on juvenile delinquents who lacked support from their families, schools, and peers in normal life and who consequently turned to socially disadvantaged groups to maintain their identity. ${ }^{18}$ Similar findings have also been identified in the mechanism of Internet addiction. $\mathrm{Yu}$ and colleagues found that when the pathway to pursuing self-worth in the real world was blocked, juveniles tended to turn to the virtual world via the Internet to maintain their self-worth. Unfortunately, once cyber-behaviors are associated with the promotion of self-worth, juveniles may become addicted to Internet use. $^{19,34,71}$

\section{Academic Achievement and Bullying Behavior: The Moderating Effect of Age Cohort}

Perceived social support is an important source of selfworth. ${ }^{18,19,34}$ However, middle and high school students may differ in terms of the effect of social support on bullying. For middle school students, social support as an important source of self-worth not only buffers psychological pressure and reduces the occurrence and persistence of aggression and bullying, ${ }^{72}$ but also moderates the impact of low academic achievement on bullying behavior. $^{37,72,73}$

However, according to Cobb's definition of social support as a network of communication and mutual obligations, ${ }^{74}$ social support may be a factor contributing to bullying among high school students. ${ }^{54,75}$ Compared to middle school students, high school students consider bullying as popular rather than undesirable behavior. ${ }^{76,77}$ These perceptions could arise from a strong motivation to seek a group identity. Therefore, social support can be an important driver of bullying. Empirical research reveals that bullies in high school tend to perceive a higher level of social support. ${ }^{38,54,75,78}$ Additionally, the importance of academic achievement compared to social support varies with age, wherein high school students with high social support may not value academics as much and instead use bullying to maintain their social status. ${ }^{79}$

As shown in Tables 1 and 2, the bullying behavior of high school students was significantly lower than that of middle school students. This is consistent with previous research showing that bullying behavior increases with age in primary school, peaks in middle school, and then decreases in high school. ${ }^{24,25,78}$

\section{Implications for Practice}

The theory of self-worth orientation not only provides a theoretical basis to understand the mechanism of bullying behavior, but also provides practitioners with advice for prevention and intervention. First, bullying is a form of instrumental aggression that allows the individual to gain respect and acceptance from others. From the perspective of self-worth orientation theory, the deeper purpose of obtaining respect and recognition from others is to pursue self-worth. Academic achievement is an important source of self-worth for adolescents; academic disadvantage is a setback for adolescents and may lead to other problems. Families and schools should avoid negative, rejecting, or alienating reactions caused by disappointment in adolescent academic achievement and pay timely attention to solve the adolescent's psychological or behavioral problems caused by academic performance.

Second, the present study demonstrates that the moderating effect of perceived social support on the relationship between academic achievement and bullying in middle school is different from that in high school. In middle school, social support may be a compensatory source of self-worth that alleviates the impact of poor academic achievement on bullying. However, in high school, social support exacerbates the impact of academic achievement on bullying. Therefore, to reduce problem behaviors among students, educators and parents need to give more support to teenagers to directly improve their confidence in coping with difficulties, enhance their sense of self-worth, and indirectly improve their learning and living psychological environment. For example, positive teacher-student relationships ${ }^{80,81}$ are conducive to reducing bullying behaviors. However, as shown in this study, the role of social support may exaggerate the relationship between academic achievement and bullying in high school, educators need to consider the possible unwanted effects of social support. 


\section{Limitations and Future Directions}

The present results support our hypothesis. However, some limitations remain. First, a cross-sectional design was adopted for this study; therefore, causality cannot be inferred. Previous studies found that bullying was both influenced by academic achievement ${ }^{18,82,83}$ and a possible cause of poor academic achievement. ${ }^{84}$ Therefore, future studies may adopt a cross-lag method to explore the influencing mechanisms in the bidirectional relationship between academic achievement and bullying. Second, this study used a selfreport to assess all the variables; thus, results may have been affected by self-serving bias and social desirability and may have incited participants to overstate their academic achievement and underestimate their bullying behavior. Future studies may adopt third-party assessments to enhance the objectivity of the measurement index. Third, adolescent bullying behaviors mainly occur in the scope of school. Future studies should focus on variables in the context of the campus, such as school atmosphere and relationships. ${ }^{80}$ Finally, due to an exam-oriented education system in China, academic achievement is one of the most important sources of self-worth for Chinese adolescents. The effect of low academic achievement on bullying behavior may vary in countries with different cultural contexts that do not emphasize exam-oriented education; thus, future research should adopt a cross-cultural paradigm to improve external validity.

\section{Conclusion}

The present study examined middle and high school students and revealed that perceived social support attenuates the impact of low academic achievement on bullying in middle school students; however, among high school students, perceived social support aggravates the effect of low academic achievement on bullying. These results support the hypothesis of the self-worth orientation theory and offer some practical solutions for the prevention of and intervention in bullying.

\section{Abbreviations}

AA, Academic achievement; PSS, perceived social support; SD, standard deviation; SE, standard error.

\section{Ethics Approval and Informed Consent}

This study was reviewed and approved by the Central China Normal University Ethics Committee, and all methods were performed in accordance with government regulations, laboratory policies, and the 1964 Helsinki
Declaration. Participants younger than 18 were approved by the ethics committee to provide informed consent on their own behalf. Informed consent was obtained from all participants included in the study.

\section{Disclosure}

The authors report no conflicts of interest in this work.

\section{References}

1. Nansel TR, Craig W, Overpeck MD, Saluja G, Ruan WJ, Bully HBSAC. Cross-national consistency in the relationship between bullying behaviors and psychosocial adjustmenT. Arch Pediatr Adolesc Med. 2004;158(8):730-736. doi:10.1001/ archpedi.158.8.730

2. Cook CR, Williams KR, Guerra NG, Kim TE, Sadek S. Predictors of bullying and victimization in childhood and adolescence: A meta-analytic investigation. Sch Psychol Quart. 2010;25(2):65-83. doi:10.1037/a0020149

3. Ba Z, Han Z, Gong Z, Li F, Zhang H, Zhang G. Ethnic differences in experiences of school bullying in China. Child Youth Serv Rev. 2019;104:104402. doi:10.1016/j.childyouth.2019.104402

4. Xie J, Xie L. A comparative study of bullying victimization in Chinese and American adolescents [In Chinese]. Chin J Clin Psychol. 2016;24(4):706-709.

5. Chen X, Huang X, Chang L, Wang L, Li D. Aggression, social competence, and academic achievement in Chinese children: A 5-year longitudinal study. Dev Psychopathol. 2010;22:583-592. doi:10.1017/S0954579410000295

6. Li L, Chen X, Li H. Bullying victimization, school belonging, academic engagement and achievement in adolescents in rural China: A serial mediation model. Child Youth Serv Rev. 2020;113:104946. doi:10.1016/j.childyouth.2020.104946

7. Stipek D, Miles S. Effects of aggression on achievement: does conflict with the teacher make it worse? Child Dev. 2008;79:1721-1735. doi:10.1111/j.1467-8624.2008.01221.x

8. Hunter GH. Comparing Bullies and Victims: who Responds to a Universal Intervention Program to Decrease Bullying Behaviors in Elementary Schools? University of Georgia; 2009.

9. Swearer SM, Siebecker AB, Johnsen-Frerichs LA, Wang C. Assessment of bullying/victimization: the problem of comparability across studies and across methodologies. In: Jimerson SR, Swearer SM, Espelage DL, editors. Handbook of Bullying in Schools: An International Perspective. Routledge; 2010:305-328.

10. Copeland WE, Wolke D, Angold A, Costello EJ. Adult psychiatric outcomes of bullying and being bullied by peers in childhood and adolescence. JAMA Psychiatry. 2013;70(4):419-426. doi:10.1001/ jamapsychiatry.2013.504

11. Ttofi MM, Farrington DP. Effectiveness of school-based programs to reduce bullying: a systematic and meta-analytic review. $J$ Exp Criminol. 2010;7(1):27-56. doi:10.1007/s11292-010-9109-1

12. Olweus D. Bully/victim problems among school-children: long-term consequences and an effective intervention program. In: Hodgins $\mathrm{S}$, editor. Mental Disorder and Crime. Sage; 1993:317-349.

13. Flouri E, Buchanan A. The role of mother involvement and father involvement in adolescent bullying behavior. J Interpers Violence. 2003;18(6):634-644. doi:10.1177/0886260503251129

14. Barriga AQ, Doran JW, Newell SB, Morrison EM, Barbetti V, Robbins DB. Relationships between problem behaviors and academic achievement in adolescents: the unique role of attention problems. $J$ Emot Behav Disord. 2002;10(4):233-240. doi:10.1177/ 10634266020100040501 
15. Connor DF. Aggression and Antisocial Behavior in Children and Adolescents: Research and Treatment. The Guilford Press; 2004.

16. Olweus D. Bullying at School: What We Know and What We Can Do. Malden, MA: Blackwell Publishing; 1993.

17. Williams S, McGee R. Reading attainment and juvenile delinquency. J Child Psychol Psychiatry. 1994;35(3):441-459. doi:10.1111/j.14697610.1994.tb01733

18. Jin S. Social Psychology. High Education Press; 2010.

19. Yu Q, Zhang L, Wu S, Guo Y, Jin S, Sun Y. The influence of juvenile preference for online social interaction on problematic Internet use: the moderating effect of sibling condition and the moderated moderating effect of age cohort. Comput Hum Behav. 2017;68:345-351. doi:10.1016/j.chb.2016.11.026

20. Jin S, Yu Q, Guo Y, Zhang L, Zhu Y, Wu G. The effect of juvenile use of online social interaction on internet addiction: the moderating effect of the family social economic status [In Chinese]. Chin Psychol Sci. 2017;40(4):885-891.

21. ASCA. The ASCA National Model: A Framework for School Counseling Programs. $3<$ sup $>\operatorname{rd}\{\{/ \sup \}\}$ ed. Author; 2012.

22. Elman BA. Civil Examinations and Meritocracy in Late Imperial China. Harvard University Press; 2013.

23. Yu CCW, Chan S, Cheng F, Sung RYT, Hau KT. Are physical activity and academic performance compatible? Academic achievement, conduct, physical activity and self-esteem of Hong Kong Chinese primary school children. Educ Stud. 2006;32(4):331-341. doi:10.1080/ 03055690600850016

24. Espelage DL, Holt MK, Henkel RR. Examination of peer-group contextual effects on aggression during early adolescence. Child Dev. 2003;74(1):205-220. doi:10.1111/1467-8624.00531

25. Pellegrini AD, Long JD. A longitudinal study of bullying, dominance, and victimization during the transition from primary school through secondary school. Br J Dev Psychol. 2002;20(2):259-280. doi: $10.1348 / 026151002166442$

26. Sijtsema JJ, Veenstra R, Lindenberg S, Salmivalli C. Empirical test of bullies' status goals: assessing direct goals, aggression, and prestige. Aggress Behav. 2009;35(1):57-67. doi:10.1002/ab.20282

27. Swearer SM, Espelage DL, Napolitano SA. Bullying Prevention and Intervention: Realistic Strategies for Schools. Guilford Press; 2009.

28. Volk AA, Veenstra R, Espelage DL. So you want to study bullying? Recommendations to enhance the validity, transparency, and compatibility of bullying research. Aggress Violent Behav. 2017;36:34-43. doi:10.1016/j.avb.2017.07.003

29. Davidson LM, Demaray MK. Social support as a moderator between victimization and internalizing-externalizing distress from bullying. Sch Psychol Rev. 2007;36(3):383. doi:10.1080/02796015.2007.12087930

30. Davis JP, Dumas TM, Merrin GJ, et al. Examining the pathways between bully victimization, depression, academic achievement, and problematic drinking in adolescence. Psychol Addict Behav. 2018;32 (6):605-616. doi:10.1037/adb0000394

31. Weidman AC, Augustine AA, Murayama K, Elliot AJ. Internalizing symptomatology and academic achievement: bi-directional prospective relations in adolescence. $J$ Res Pers. 2015;58:106-114. doi:10.1016/j.jrp.2015.07.005

32. Wienke Totura CM, Green AE, Karver MS, Gesten EL. Multiple informants in the assessment of psychological, behavioral, and academic correlates of bullying and victimization in middle school. $J$ Adolesc. 2009;32(2):193-211. doi:10.1016/j.adolescence.2008.04.005

33. Jiang Q. Perceived Social Support Scale [In Chinese]. Chin J Ment Health. 1999;13:131-133.

34. Jin S, Shan W. New Progress in Psychological Research. Beijing Normal University Press; 2011.

35. Berkman LF, Glass T, Brissette I, Seeman TE. From social integration to health: durkheim in the new millennium. Soc Sci Med. 2000;51(6):843-857. doi:10.1016/s0277-9536(00)00065-4

36. Cohen S. Social relationships and health. Am Psychol. 2004;59 (8):676-684. doi:10.1037/0003-066x.59.8.676
37. Cohen S, Wills TA. Stress, social support, and the buffering hypothesis. Psychol Bull. 1985;98(2):310-357. doi:10.1037/00332909.98.2.310

38. Demaray MK, Malecki C. Perceptions of the frequency and importance of social support by students classified as victims, bullies, and bully/victims in an urban middle school. Sch Psychol Rev. 2003;32 (3):471-490. doi:10.1080/02796015.2003.12086213

39. Dumont M, Provost MA. Resilience in adolescents: protective role of social support, coping strategies, self-esteem, and social activities on experience of stress and depression. J Youth Adolesc. 1999;28 (3):343-363. doi:10.1023/a:1021637011732

40. Kleiman EM, Liu RT. Social support as a protective factor in suicide: findings from two nationally representative samples. $J$ Affect Disord. 2013;150(2):540-545. doi:10.1016/j.jad.2013.01.033

41. Li D, Guo Y, Zhang L, et al. Fluid self-worth: the compensatory role of online social interaction. Child Youth Serv Rev. 2020:105536. doi:10.1016/j.childyouth.2020.105536.

42. Grant KE, O'koon JH, Davis TH, et al. Protective factors affecting low-income urban african american youth exposed to stress. $J$ Early Adolesc. 2000;20(4):388-417. doi:10.1177/0272431600020004002

43. Erikson E. Identity and the Life Cycle. International Universities Press; 1959.

44. Hartnett S. Does peer group identity influence absenteeism in high school students? High Sch J. 2007;91(2):35-44. doi:10.1353/hsj.2008.0000

45. Newman PR, Newman BM. Early adolescence and its conflict: group identity versus alienation. Adolescence. 1976;42(11):261-274.

46. Bradshaw CP, Sawyer AL, O'Brennan LM. Bullying and peer victimization at school: perceptual differences between students and school staff. Sch Psychol Rev. 2007;36(3):361-382. doi:10.1080/ 02796015.2007.12087929

47. Horne AM, Orpinas P, Newman-Carlson D, Bartolomucci CL. Elementary school bully busters program: understanding why children bully and what to do about it. In: Espelage DL, Swearer SM, editors. Bullying in American Schools: A Social-Ecological Perspective on Prevention and Intervention. Mahwah, NJ: Lawrence Erlbaum; 2004:297-325.

48. Perren S, Hornung R. Bullying and delinquency in adolescence: victims' and perpetrators' family and peer relations. Swiss J Psychol. 2005;64(1):51-64. doi:10.1024/1421-0185.64.1.51

49. Archer J. Does sexual selection explain human sex differences in aggression? Behav Brain Sci. 2009;32(3-4):249-311. doi:10.1017/ S0140525X09990951

50. Bradshaw CP, Waasdorp TE, Johnson SL. Overlapping verbal, relational, physical, and electronic forms of bullying in adolescence: influence of school context. J Clin Child Adolesc Psychol. 2014;44 (3):494-508. doi:10.1080/15374416.2014.893516

51. Kaltiala-Heino R, RimpelÄ M, Rantanen P, RimpelÄ A. Bullying at school - an indicator of adolescents at risk for mental disorders. J Adolesc. 2000;23(6):661-674. doi:10.1006/jado.2000.0351

52. Nansel TR, Overpeck MD, Pilla RS, Ruan WJ, Simons-Morton B, Scheidt P. Bullying Behaviors Among US Youth-Prevalence and Association with Psychosocial Adjustment. American Medical Association (AMA); 2001.

53. Buss D. Evolutionary Psychology: The New Science of the Mind. 4<sup $>$ th $\{\{/ \sup \}\}$ ed ed. Psychology Press; 2014.

54. Espelage DL, Holt MK. Bullying and victimization during early adolescence: peer influences and psychosocial correlates. J Emot Abuse. 2001;2(23):123-142. doi:10.1300/j135v02n02_08

55. Pekrun R, Lichtenfeld S, Marsh HW, Murayama K, Goetz T. Achievement emotions and academic performance: longitudinal models of reciprocal effects. Child Dev. 2017;88(5):1653-1670. doi:10.1111/cdev.12704

56. Sisk VF, Burgoyne AP, Sun J, Butler JL, Macnamara BN. To what extent and under which circumstances are growth mind-sets important to academic achievement? Two meta-analyses. Psychol Sci. 2018;29(4):549-571. doi:10.1177/0956797617739704 
57. Gray EK, Watson D. General and specific traits of personality and their relation to sleep and academic performance. J Pers. 2002;70 (2):177-206. doi:10.1111/1467-6494.05002

58. Lee KM, Jones MK, Day SX. The impact of academic competency teasing and self-concept on academic and psychological outcomes among gifted high school students. Learn Individ Differ. 2017;56:151-158. doi:10.1016/j.lindif.2016.10.020

59. Postmes T, Haslam SA, Jans L. A single-item measure of social identification: reliability, validity, and utility. $\mathrm{Br} J$ Soc Psychol. 2013;52(4):597-617. doi:10.1111/bjso.12006

60. Olweus D. The Revised Bully/Victim Questionnaire. University of Bergen; 1996.

61. Zhang W. Prevalence and major characteristics of bullying/victimization among primary and junior middle school children [In Chinese]. Acta Psychol Sin. 2002;34(4):57-64.

62. Zhang W, Wu J, Jones K. Revision of the Chinese version of olweus child bullying questionnaire [In Chinese]. Psychol Dev Educ. 1999;15(2):7-11.

63. Zimet GD, Powell SS, Farley GK, Werkman S, Berkoff KA. Psychometric characteristics of the multidimensional scale of perceived social support. J Pers Assess. 1990;55(34):610-617. doi:10.1080/00223891.1990.9674095

64. Lian S, Sun X, Tian Y, Yan J, Niu G, Tong Y. The effect of adolescents' peer attachment on depression: the mediating role of friends social support and self-esteem [In Chinese]. J Psychol Sci. 2016;39(5):1116-1122.

65. Yan B, Zheng X. Researches into relations among social-support, self-esteem and subjective well-being of college students [In Chinese]. Psychol Dev Educ. 2006;22(3):60-64.

66. Podsakoff PM, MacKenzie SB, Podsakoff NP. Sources of method bias in social science research and recommendations on how to control it. Annu Rev Psychol. 2003;63:39-569. doi:10.1146/annurevpsych-120710-100452

67. Aiken LS, West SG, Reno RR. Multiple Regression: Testing and Interpreting Interactions. Thousand Oaks: Sage Publisher; 1991.

68. de Bruyn EH, Cillessen AHN, Wissink IB. Associations of peer acceptance and perceived popularity with bullying and victimization in early adolescence. $J$ Early Adolesc. 2009;30(4):543-566. doi: $10.1177 / 0272431609340517$

69. Reijntjes A, Vermande M, Olthof T, et al. Costs and benefits of bullying in the context of the peer group: a three wave longitudinal analysis. J Abnorm Child Psychol. 2013;41(8):1217-1229. doi:10.1007/s10802-013-9759-3

70. Baltes PB, Lindenberger U, Staudinger UM. Life span theory in developmental psychology. In: Lener RM, editor. Theoretical Models of Human Developments: Handbook of Child Psychology. 6th ed ed. Wiley; 2006:569-664.

71. Li L, Yu Q, Zhang L, Jin S. The gender difference on internet addictive among adolescent: the mediation effect of the differentiation of social and psychological situation in school [In Chinese]. Chin J Clin Psychol. 2015;6:1044-1048.
72. Eşkisu M. The relationship between bullying, family functions, perceived social support among high school students. Procedia Soc Behav Sci. 2014;159:492-496. doi:10.1016/j.sbspro.2014.12.412

73. Rigby K, Slee PT. Suicidal ideation among adolescent school children, involvement in bully/victim problems, and perceived low social support. Suicide Life Threat Behav. 1999;29:119-130. doi:10.1111/ j.1943-278X.1999.tb01050.x

74. Cobb S. Social support as a moderator of life stress. Psychosom Med. 1976;38(5):300-314. doi:10.1097/00006842-197609000-00003

75. Ballatore RM, Paccagnella M, Tonello M. Bullied because younger than my mates? The effect of age rank on victimisation at school. Labour Econ. 2020;62:101772. doi:10.1016/j.labeco.2019.101772

76. LaFontana KM, Cillessen AHN. Developmental changes in the priority of perceived status in childhood and adolescence. Soc Dev. 2010;19(1):130-147. doi:10.1111/j.1467-9507.2008.00522.x

77. Swearer SM, Cary PT. Perceptions and attitudes toward bullying in middle school youth:a developmental examination across the bully/ victim continuum. J Appl Sch Psychol. 2003;19(2):63-79. doi:10.1300/j008v19n02_05

78. Holt MK, Espelage DL. Perceived social support among bullies, victims, and bully-victims. J Youth Adolesc. 2007;36(8):984-994. doi:10.1007/s10964-006-9153-3

79. Volk AA, Provenzano DA, Farrell AH, Dane AV, Shulman EP. Personality and bullying: pathways to adolescent social dominance. Curr Psychol. 2019;(2):1-12. doi:10.1007/s12144-019-00182-4

80. Longobardi C, Settanni M, Lin S, Fabris MA. Student-teacher relationship quality and prosocial behaviour: the mediating role of academic achievement and a positive attitude towards school. $\mathrm{Br} J$ Educ Psychol. 2020;9. doi:10.1111/bjep.12378

81. Longobardi C, Settanni M, Prino LE, Fabris MA, Marengo D. Students' psychological adjustment in normative school transitions from kindergarten to high school: investigating the role of teacherstudent relationship quality. Front Psychol. 2019;10:381238. doi:10.3389/fpsyg.2019.01238

82. Agnich LE, Miyazaki Y. A multilevel cross-national analysis of direct and indirect forms of school violence. $J$ Sch Violence. 2013;12:319-339. doi:10.1080/15388220.2013.807737

83. Lacey A, Cornell D. The impact of teasing and bullying on schoolwide academic performance. $J$ Appl Sch Psychol. 2013;29 (3):262-283. doi:10.1080/15377903.2013.806883

84. Evans CBR, Smokowski PR, Rose RA, Mercado MC, Marshall KJ. Cumulative bullying experiences, adolescent behavioral and mental health, and academic achievement: an Integrative model of perpetration, victimization, and bystander behavior. J Child Fam Stud. 2018;5. doi:10.1007/s10826-018-1078-4
Psychology Research and Behavior Management

\section{Publish your work in this journal}

Psychology Research and Behavior Management is an international, peer-reviewed, open access journal focusing on the science of psychology and its application in behavior management to develop improved outcomes in the clinical, educational, sports and business arenas. Specific topics covered in the journal include: Neuroscience, memory and decision making; Behavior modification and management; Clinical applications; Business and sports performance management; Social and developmental studies; Animal studies. The manuscript management system is completely online and includes a very quick and fair peer-review system, which is all easy to use. Visit http://www. dovepress.com/testimonials.php to read real quotes from published authors. 